\title{
Plasma level of LDL-cholesterol at diagnosis is a predictor factor of breast tumor progression
}

\author{
Catarina Rodrigues dos Santos ${ }^{1,25^{*}}$, Isabel Fonseca ${ }^{3,5}$, Sérgio Dias ${ }^{4,5}$ and JC Mendes de Almeida 2,5
}

\begin{abstract}
Background: Among women, breast cancer (BC) is the leading cancer and the most common cause of cancer-related death between 30 and 69 years. Although lifestyle and diet are considered to have a role in global BC incidence pattern, the specific influence of dyslipidemia in BC onset and progression is not yet completely understood.

Methods: Fasting lipid profile (total cholesterol, LDL-C, HDL-C, and triglycerides) was prospectively assessed in 244 women with $\mathrm{BC}$ who were enrolled according to pre-set inclusion criteria: diagnosis of non-hereditary invasive ductal carcinoma; selection for surgery as first treatment, and no history of treatment with lipid-lowering or antidiabetic drugs in the previous year. Pathological and clinical follow-up data were recorded for further inclusion in the statistical analysis.
\end{abstract}

Results: Univariate associations show that BC patients with higher levels of $L D L-C$ at diagnosis have tumors that are larger, with higher differentiation grade, higher proliferative rate (assessed by Ki67 immunostaining), are more frequently Her2-neu positive and are diagnosed in more advanced stages. Cox regression model for disease-free survival (DFS), adjusted to tumor T and N stages of TNM classification, and immunohistochemical subtypes, revealed that high LDL-C at diagnosis is associated with poor DFS. At 25 months of follow up, DFS is 12\% higher in BC patients within the third LDL-C tertile compared to those in the first tertile.

Conclusions: This is a prospective study where LDL-C levels, at diagnosis, emerge as a prognostic factor; and this parameter can be useful in the identification and follow-up of high-risk groups. Our results further support a possible role for systemic cholesterol in BC progression and show that cholesterol metabolism may be an important therapeutic target in BC patients.

Keywords: LDL-cholesterol, Breast cancer, Tumor progression

\section{Background}

Cancer and cardiovascular diseases are the leading causes of death in Europe [1] and USA [2] and their incidence is increasing also in Asia [3,4].

In what concerns cancer, breast cancer $(\mathrm{BC})$ is the most frequent diagnosed each year in Europe and USA (age-adjusted incidence rate, 76-89,7 per 100,000) [5] and the most common cause of cancer-related death between 30 and 69 years [4]. In Asia, incidence rate of $\mathrm{BC}$ is lower (age-adjusted incidence rate, 22-30 per 100,000) [5] but is dramatically raising $[4,6]$.

\footnotetext{
* Correspondence: catarinarsantos@hotmail.com

'Gulbenkian Programme for Advanced Medical Education, Lisbon, Portugal ${ }^{2}$ Department of Surgical Oncology, Instituto Português de Oncologia de Lisboa, Francisco Gentil, Lisbon, Portugal

Full list of author information is available at the end of the article
}

Lifestyle and diet are frequently indicated as reasons for the global distribution of BC incidence. Nevertheless, while dyslipidemia [high LDL-C (low density lipoprotein cholesterol) and low HDL-C (high density lipoprotein cholesterol) levels] was already shown to play a major role in the etiopathogenesis of cardiovascular diseases [7], mainly attributed to diet, the specific influence of dyslipidemia in BC initiation and progression is not completely understood.

Cholesterol is a structural component of the cell membrane, specially localized in lipid rafts - membrane microdomains that assemble the signal transduction machinery and associate to proteins implicated in key cellular signaling pathways. Many of these pathways closely associate with malignant transformation due to their influence in 
organization of the cytoskeleton, cell polarity and angiogenesis $[8,9]$.

Furthermore, cholesterol is also a steroid hormone precursor and the vast majority of $\mathrm{BC}$ is known to be hormone responsive [10]. The peak incidence of $\mathrm{BC}$ occurs in the perimenopausal age [11], when women dyslipidemia prevalence also rises [12].

Several authors have shown that lipoprotein fractions can induce cancer cells proliferation and migration in vitro [13-19] and oxysterol 27-hydroxycholesterol, a primary metabolite of cholesterol was shown to promote ER-positive BC growth in in vivo models [20]. Moreover, studies in genetic or diet induced hypercholesterolemic mouse models also demonstrated a clear association between high lipid levels and BC development [21] and progression [22,23].

However, clinical data have provided contradictory results. Prospective studies showed positive association between total cholesterol (TC) levels and both $\mathrm{BC}$ incidence [24-26] and increased overall mortality in BC patients [27]; but also no association at all [28-33] or even inverse associations between TC levels and incidence of premenopausal BC [34-36]; as well as a protective effect of very high levels of TC [37].

LDL-C and HDL-C are lipoproteins responsible for the cholesterol transportation, LDL-C from the liver to peripheral tissues and HDL-C for the reverse transportation [38]. Studies specifically addressing the relation of lipoproteins fractions are similarly contradictory. Regarding HDL-C, some show a positive association between low HDL-C levels and increased BC risk [29,39-42] and a protective effect of high HDL to premenopausal BC [43]; while others find no association [44-46], and some even report a positive correlation between high HDL-C and BC risk [47,48]. LDL-C is less studied and no association with BC risk was reported [29,31]. Triglycerides levels were no longer associated with risk in prospective studies except, when in combination with low HDL $[33,43]$.

Different study designs, study populations and endpoints, duration of follow up, timing of cholesterol measurements, tumor stage and histological type, and differences in statistical adjustment for confounding variables may account for the disparity in the results of these studies.

Although the inconsistency of the studies in the influence of plasma cholesterol on $\mathrm{BC}$ risk, alterations in lipid profile, are often seen among $\mathrm{BC}$ patients, when compared to non-cancer controls. Increased TC levels are transversal to all studies [41,49-54] with the exception to advanced cases in two studies $[55,56]$. Triglycerides and LDL, when measured, were also constantly raised while HDL level was decreased [41,49-54,57].

So, whereas from the epidemiological point of view, the influence of plasma cholesterol in $\mathrm{BC}$ initiation has been difficult to demonstrate, the variations of lipid profile in $\mathrm{BC}$ patients and controlled experimental studies suggest a role of cholesterol in $\mathrm{BC}$ progression.

In the present study we hypothesized that the host cholesterol-enriched macroenvironment, promotes breast tumor progression. To answer this question we prospectively assessed the lipid profile in a cohort of women with $\mathrm{BC}$, at diagnosis, and correlated these levels with clinical and pathological data collected thereafter.

\section{Methods}

\section{Study population and data collection}

From January to December 2011, women, who underwent for operable BC at the Breast Unit of Instituto Português de Oncologia de Lisboa, Francisco Gentil (IPOLFG), were prospectively assembled.

Women were included if they met the following criteria: 1) invasive ductal carcinoma (currently named invasive carcinoma NOS [58]), confirmed by biopsy; 2) surgery as the first treatment; 3) informed consent. Women were excluded if they had: 1) previous treatment (chemotherapy, radiotherapy, hormonotherapy); 2) hereditary $\mathrm{BC}$ (confirmed by genetic analysis) or 3 ) were taking lipid-lowering, anti-diabetic drugs (statins, fibrates, oral anti diabetics, Insulin) or corticosteroids in the previous year. The study was approved by the Ethics Committee of the IPOLFG.

Demography, risk factors [menopausal status, body mass index (BMI), age, family history, parity, breast feeding] and clinical examination were recorded in the first interview.

Treatment was determined by the clinicopathological stage and patient characteristics according to the institutional protocols (following NCCN guidelines [59]), without changes related to the study.

Follow up, after surgery and adjuvant treatment (when appropriate), was scheduled every 6 months for 2 years and annual thereafter. Mammography was performed 1 year after surgery and then repeated yearly.

\section{Biospecimen collection and plasma lipid and lipoproteins assays}

Fasting lipid profile was measured at diagnosis, along with routine preoperative exams. Blood was collected into EDTA-coated tubes and the plasma levels of total cholesterol (TC), low density lipoprotein (LDL-C), high density lipoprotein (HDL-C) and triglycerides were measured automatically by electrophoresis (Architect ci8200 analyzer; Abbott Diagnostics, Wiesbaden, Germany) at the certified Clinical Pathology Laboratory of IPOLFG.

\section{Pathology and Immunohistochemistry}

Hormonal receptors were measured using standardized immunohistochemistry. Her2-neu receptor was scored 
according to the World Health Organization guidelines [60] from 0 to $3+$. All cases with $2+$ score were reevaluated using chromogenic in situ hybridation. Immunohistochemical staining for Ki 67 was performed in a Dako Autostainer $^{\circledast}$ (Dako, Glostrup, Denmark) using standard protocols, followed by counting positive cells in an automated cellular imaging system (ACIS ${ }^{\circledR}$ II, Dako, Glostrup, Denmark I). Technicians were blinded to the lipid profile status of the study participants.

\section{Statistical analysis}

Continuous variables are presented as mean (standard deviation) or median (interquartile range) if they have normal distribution or not, respectively. For categorical variables absolute values and frequencies are shown.

Spearman rank correlations coefficients were calculated to examine correlations between continuous variables.

Univariate analysis between lipid profile, BC risk factors [status, body mass index (BMI), age, family history, parity, breast feeding] and traditional prognostic factors [tumor size, positive lymph nodes, tumor grade, lymphovascular invasion (LVI), estrogen receptor (ER), progesterone receptor (PR), Her2-neu receptor (HER2) and Ki 67] were performed using parametric tests to variables with normal distribution and non-parametric tests to variables without normal distribution.

Multivariate logistic regression to the risk of tumor $\mathrm{T}$ stage included the following variables: TC (by tertiles), LDL (by tertiles), Triglycerides (3rd tertile), BMI (by tertiles) and age (by tertiles) by using stepwise conditional forward analysis method (entry 0,05; removal 0,10).

Kaplan-Meier curves were used to determine overall survival (OS) and disease-free survival (DFS) rates with use of log rank tests. Cox proportional hazards models were used to estimate hazard ratios with $95 \%$ confidence intervals (CI), relating LDL level to DFS. Multivariate Cox model was adjusted to tumor $\mathrm{T}$ stage, $\mathrm{N}$ stage and subtype.

To assess the internal validity of our results we examined the association of lipid profile with BMI and age. The association of BMI and tumor characteristics, as well as OS and DFS adjusted to BMI were also determined.

For statistical purposes, cases were censored at the date of disease progression confirmation, death or at June 9th, 2013, whichever came first.

Likelihood ratio $P$ values are reported to whole variables in the model. All $P$ values are two-tailed.

The statistical analysis was done using IBM SPSS Statistics for Windows, Version 19.0(Armonk, NY: IBM Corp. Released 2010).

\section{Results}

A total of 446 women were potential assembled to the study. Of those, 202 were excluded for being on conflicting medications $(n=134)$, for BC histological type $(n=60)$ and previous treatments $(n=9)$. Baseline demographic, clinical and tumor related characteristics of the study population $(\mathrm{n}=244)$ are listed in Table 1.

All women underwent surgery, being the majority treated with breast-conserving surgery $(73,8 \%) ; 78,3 \%$ had adjuvant radiotherapy; $67,7 \%$ had systemic chemotherapy; $11,9 \%$ are under trastuzumab and $70,1 \%$ are under hormone therapy (Additional file 1).

During follow up, 1 woman had local disease relapse, 16 women had systemic dissemination and 9 died (7 from confirmed disease progression) (Additional file 2).

\section{Spearman correlations}

Exploratory correlations between lipid profile, age, BMI, primary tumor size and lymph node metastasis ratio (defined as the number of metastatic axillary lymph nodes, over the total lymph nodes removed), showed that systemic levels of LDL-C and TC correlates positively with tumor size (Spearman $\mathrm{r}=0,199, P$ 0,002; Spearman $\mathrm{r}=$ $0,145, P$ 0,025, respectively). As expected, age correlates with BMI (Spearman $\mathrm{r}=0,155, P$ 0,022) and triglycerides (Spearman $r=0,312, P<0,0001)$ and BMI correlates with age, LDL-C (Spearman $r=0,161, P$ 0,018), HDL (Spearman $\mathrm{r}=-0,157, P 0,021)$ and triglycerides (Spearman $\mathrm{r}=0,149$, $P$ 0,027).

Plasma LDL-C level was significantly related to tumor $\mathrm{T}$ stage and prognostic groups of the American Joint Committee on Cancer [58]. There was no statistical difference in other parameters of lipid profile across tumor stages (Additional file 3) and we did not find correlations between pathological or clinical data and lipid profile variables (Additional file 4).

\section{Univariate associations}

Population was stratified based on LDL-C level tertiles: LDL T1:LDL-C $\leq 117 \mathrm{mg} / \mathrm{dl}$; LDL T2:144 mg/dl $\geq$ LDLC > $117 \mathrm{mg} / \mathrm{dl}$; LDL T3:LDL-C > 144 mg/dl. Patients in the third LDL-C tertile have larger tumors $(P$ 0,024) (Figure 1A), of higher differentiation grade $(P 0,027)$, with higher proliferative rate $(P 0,017)$, and are diagnosed in more advanced stages. This analysis does not demonstrate differences in lipid profiles between breast tumor immunohistochemical subtypes (Luminal A, Luminal B, Triple negative and HER2 type [61]). Nevertheless, tumors of patients in the third LDL-C tertile are more commonly Her2-neu positive, when compared to others tertiles $(P 0,002)$ (Figure 1B). There are no differences, between LDL-C categories, concerning studied BC risk factors (Additional file 5).

\section{Multivariate logistic regression}

A multivariate logistic regression to the risk of tumor $\mathrm{T}$ stage was then modeled. All the variables significantly 
Table 1 Clinical and tumor-related characteristics of the study population $(\mathrm{N}=244)$

\begin{tabular}{|c|c|c|c|}
\hline Characteristics & & No. of patients & $\%^{1}$ \\
\hline \multicolumn{4}{|l|}{ Patient characteristics } \\
\hline Age (Years), mean \pm SD (range) & $58,2 \pm 13,3(29-91)$ & & \\
\hline Weight $(\mathrm{Kg})$, median (interquartile range) & $67(60-76)$ & & \\
\hline Height $(\mathrm{cm})$, median (interquartile range) & $160(154-163)$ & & \\
\hline BMI $\left(\mathrm{Kg} / \mathrm{m}^{2}\right)$, median (interquartile range) & $26,7(23,5-30,44)$ & & \\
\hline Menopausal status (yes) & & 126 & 65,6 \\
\hline Gestation (yes) & & 182 & 90,54 \\
\hline Breast-feeding (yes) & & 146 & 79,3 \\
\hline Oral contraception/HT (yes) & & 96 & 55,6 \\
\hline Family history of $\mathrm{BC} \#$ (yes) & & 56 & 27,5 \\
\hline $\mathrm{TC}(\mathrm{mg} / \mathrm{dL})$, median (interquartile range) & $209,5(191-231)$ & & \\
\hline HDL-C (mg/dL), median (interquartile range) & $53(46-60)$ & & \\
\hline LDL-C (mg/dL), median (interquartile range) & $128(110-153)$ & & \\
\hline Triglycerides (mg/dL), median (interquartile range) & $94(74,5-126)$ & & \\
\hline \multicolumn{4}{|l|}{ Tumor characteristics ${ }^{2}$} \\
\hline Histological type & IDC & 244 & 100 \\
\hline Tumor size $(\mathrm{mm})$, median (interquartile range) & $21(14-30)$ & & \\
\hline \multirow[t]{3}{*}{ Tumor stage $(\mathrm{T})$} & $\mathrm{T} 1, \leq 2 \mathrm{~cm}$ & 122 & 50 \\
\hline & $\mathrm{T} 2,2-5 \mathrm{~cm}$ & 115 & 47,2 \\
\hline & $\mathrm{T} 3,>5 \mathrm{~cm}$ & 7 & 2,8 \\
\hline \multirow[t]{3}{*}{ Tumor differentiation grade } & G1 & 27 & 12,4 \\
\hline & G2 & 134 & 61,5 \\
\hline & G3 & 57 & 26,2 \\
\hline \multirow[t]{3}{*}{ Immunohistochemical subtypes } & ER/PR positive & 204 & 83,9 \\
\hline & Triple negative & 23 & 9,5 \\
\hline & HER 2 Type & 16 & 6,6 \\
\hline LVI positive & & 61 & 29,2 \\
\hline \multirow[t]{4}{*}{ Nodal stage $(\mathrm{N})$} & No & 137 & 56,9 \\
\hline & N1, 1-3 LN+ & 72 & 29,9 \\
\hline & $\mathrm{N} 2,4-9 \mathrm{LN}+$ & 18 & 7,47 \\
\hline & $\mathrm{N} 3, \geq 10 \mathrm{LN}+$ & 14 & 5,8 \\
\hline \multirow[t]{3}{*}{ Clinical stage } & I & 84 & 34,4 \\
\hline & II & 125 & 51,3 \\
\hline & III & 35 & 14,3 \\
\hline Bilaterality (yes) & & 10 & 4,1 \\
\hline
\end{tabular}

\footnotetext{
${ }^{1}$ Frequency of known cases.
}

${ }^{2}$ Tumor characteristics based on The American Joint Committee on Cancer [58].

Histological type of breast cancer (IDC is presently named invasive carcinoma, NOS); Tumor Stage T of TNM Classification (T1 $\leq 2 \mathrm{~cm}$; T2:2-5cm; T3>5 cm); Tumor Differentiation Grade of Nothingham Histologic Score (G1, G2, G3); Immunohistochemical subtypes [Luminal A and B (ER/PR positive); Triple negative (ER/PR negative and Her2-neu negative); HER2 Type (ER/PR negative and Her2-neu positive)]; Pathological axillar Nodal Stage of TNM Classification (N0: no metastatic LN; N1: 1-3 metastatic LN; N2:4-9 metastatic lymph nodes; N3 10 metastatic lymph nodes); Clinical Stage or Prognostic Stages Groups of American Joint Committee on Cancer (I, II, III,IV). HT: Hormonal Therapy; BC: Breast Cancer; BMI: Body Mass Index; HT: Hormonal Therapy; TC: Total Cholesterol; LDL-C: Low Density Lipoprotein; HDL-C: High Density Lipoprotein IDC: Invasive Ductal Carcinoma; ER: Estrogen Receptor; PR: Progesterone Receptor; LVI: Lymphovascular Invasion; LN: Lymph Nodes. 


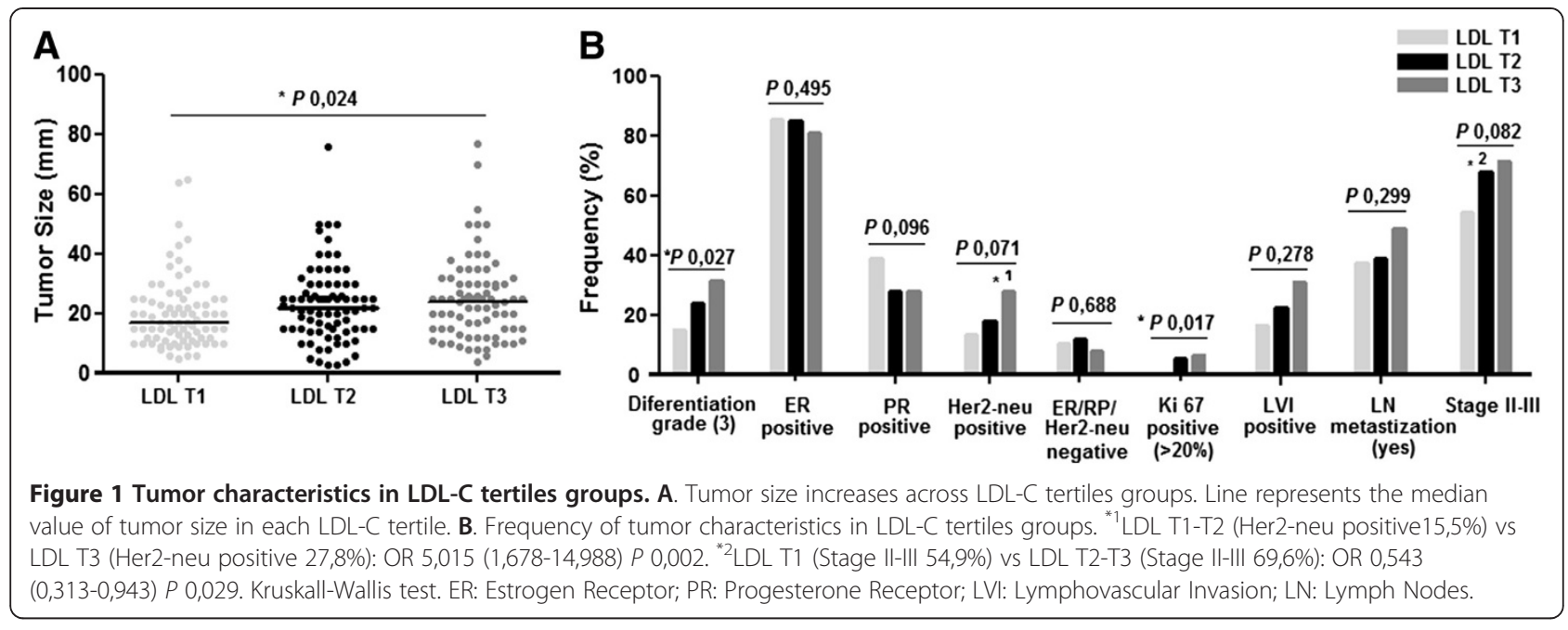

associated at univariate analysis (Additional file 6) were introduced. Age and BMI, even not positively associated, were also included because of its strong correlation with lipid profile. It was found that the LDL-C level $>$ is a predictor factor to tumor size $\geq 20 \mathrm{~mm}$, at diagnosis (Table 2).

\section{Survival and cox regression model}

At 25 months of follow up the DFS in LDL T1, LDL T2 and LDL T3 groups was $100 \%, 90,6 \%$ and $88,3 \%$, respectively (log rank test 0,013 ) (Figure 2A). OS had no statistically significant differences between LDL-C tertiles groups (Figure 2B).

Cox regression model to DFS, adjusted to tumor $\mathrm{T}$ and $\mathrm{N}$ stages, and $\mathrm{BC}$ immunohistochemical subtypes, revealed that LDL-C higher than $117, \mathrm{mg} / \mathrm{dL}$, at diagnosis, is associated with poor disease-free survival (HR 0,129; CI 0,017-0, 978, P 0,048) (Table 3).

\section{Discussion}

Multiple epidemiological studies exploring causal associations between dyslipidemia and $\mathrm{BC}$ incidence produced contradictory results [24-37]. Several methodological aspects may explain the diverse conclusions, but the influence of cholesterol in $\mathrm{BC}$ risk remains to be clinical demonstrated.
Nevertheless, biological clues from laboratory [13-19] and in vivo pre-clinical studies [20-23], as well as significant alterations in lipid profile of BC patients compared to healthy controls $[41-49,56,57,62,63]$, are very suggestive for a role of cholesterol in BC progression.

In the present study, fasting lipid profile (with discrimination between lipids and lipoproteins fractions) was prospectively assessed in a cohort of patients with invasive carcinoma, in initial stages, before any treatment and with no history of being on antidiabetic or lipid lowering drugs (including statins, fibrates, oral antidiabetics, insulin or corticosteroids). Population characteristics are similar to other series, concerning to demographic and tumor characteristics [64-66]. A slight under-representation of triple negative and HER2 type cancer have occurred due to the inclusion criteria, as those patients are more likely to undergo neoadjuvant chemotherapy. The average lipid profile of $\mathrm{BC}$ patients in this cohort superimposes that of the sex, age and BMI-matched portuguese population $[67,68]$.

Results show that systemic LDL-C level above $117 \mathrm{mg} / \mathrm{dL}$ is a predictive factor of tumor $\mathrm{T}$ stage, at diagnosis. These levels are also positively associated with worse prognostic characteristics such as higher histological grade, higher proliferative rate [69] and more advanced clinical stage (II-III). Patients in the third tercile (LDL-C $>144 \mathrm{mg} / \mathrm{dl}$ )

Table 2 Univariate and multivariate logistic regression to the risk of tumor size $\geq \mathbf{2 0} \mathbf{m m}$

\begin{tabular}{|c|c|c|c|c|c|c|}
\hline \multirow[b]{2}{*}{ Variable } & \multicolumn{3}{|c|}{ Univariate analysis } & \multicolumn{3}{|c|}{ Multivariate analysis } \\
\hline & $H R$ & $95 \% \mathrm{Cl}$ & $P$ value & $H R$ & $95 \% \mathrm{Cl}$ & $P$ value \\
\hline Total cholesterol $\mathrm{T} \geq 2 \mathrm{vs} \mathrm{T} 1$ & 1,912 & $1,113-3,285$ & 0,018 & & & \\
\hline LDL-C (>117mg/dl) T $\geq 2$ vs T1 & 2,419 & $1,394-4,199$ & 0,002 & 2,468 & $1,356-4,491$ & 0,003 \\
\hline Triglycerides $T 3$ & 1,888 & $1,092-3,264$ & 0,022 & & & \\
\hline BMI $T \geq 2$ vs $T 1$ & 1,785 & $0,010-3,155$ & 0,045 & & & \\
\hline Age $T \geq 2 v s T 1$ & 0,833 & $0,430-1,416$ & 0,499 & & & \\
\hline
\end{tabular}

LDL-C: Low Density Lipoprotein; BMI: body mass index; HR: hazard ratio, Cl: confidence interval. 

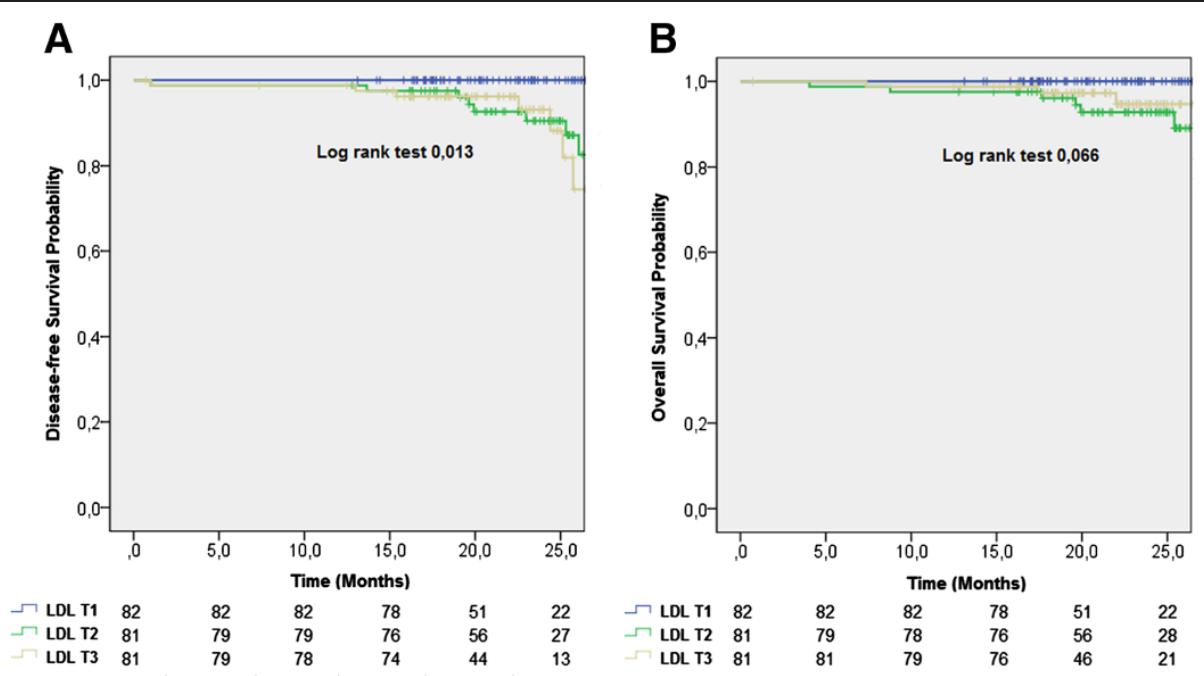

Figure 2 Overall and disease-free survival in LDL-C tertiles groups. Kaplan-Meier Curves. A. At 25 months, overall survival is $100 \%$ in LDL T1, 92,8\% in LDL T2 and 97,2\% in LDL T3 (Log rank test P 0,066). B. At 25 months, disease-free survival is 100\% in LDL T1, 90,6\% in LDL T2 and 88,3\% in LDL T3 (Log rank test 0,013).

are also more prone to have LVI and lymph node metastasis. This trend seems to be transversal to all immunohistochemical BC subtypes, although we found a significant higher number of Her2-neu positive cases in patients of the third tertile group.

Other published studies, also focused on assessing lipid profile in $\mathrm{BC}$ patients, found higher TC levels in BC patients, compared to healthy control patients $[50,52]$ and also an association between increased TC, LDL-C and decreased HDL-C levels with increasing tumor stage [50].

To our knowledge this is the first cohort of $\mathrm{BC}$ patients in which the correlation of lipid profile and tumor characteristics was done in a setting of pre-treatment and with all patients free of lipid lowering drugs. Despite we did not accessed variables that may also influence the lipid profile such as smoking habits, type of diet, residence area or socioeconomic status, the most important

Table 3 Cox multivariate regression model for disease-free survival

\begin{tabular}{|c|c|c|c|}
\hline Variable & $H R$ & $95 \% \mathrm{Cl}$ & $P$ value \\
\hline Tumor T stage $(\geq \mathrm{T} 2)$ & 0,822 & $0,264-2,565$ & 0,736 \\
\hline Tumor $\mathbf{N}$ stage $(\geq \mathrm{N} 1)$ & 0,551 & $0,201-1,515$ & 0,248 \\
\hline LDL-C (> 117 mg/dL) & 0,129 & $0,017-0,978$ & 0,048 \\
\hline Luminal A (yes) & 0,599 & $0,072-5,017$ & 0,637 \\
\hline Luminal B (yes) & 0,532 & $0,047-6,026$ & 0,610 \\
\hline Triple negative (yes) & 0,128 & $0,015-1,111$ & 0,062 \\
\hline HER2 type (yes) ${ }^{a}$ & - & - & - \\
\hline
\end{tabular}

${ }^{\mathrm{a}}$ Degree of freedom reduced because of constant or linearly dependent covariates.

LDL-C: Low Density Lipoprotein; T and N: TNM stages; HR: hazard ratio, $\mathrm{Cl}$ : confidence interval. co-variables, BMI, age and lipid lowering drugs were controlled.

Furthermore, we prospectively followed-up the patients, and at 25 months of follow up, overall survival did not evidenced differences but DFS of the patients in the third LDL-C tertile, at diagnosis was significantly reduced $(88,3 \%$ vs $100 \%, P$ 0,013). Differences of DFS in the LDL tertiles groups, adjusted to BMI remains statistically significant (Additional file 7). Cox regression model shows that LDL$\mathrm{C}$ level at diagnosis is inversely correlated with DFS, even considering tumor $\mathrm{T}$ and $\mathrm{N}$ stages and immunohistochemical subtypes covariates.

We found that LDL-C fraction is significantly associated with $\mathrm{BC}$ progression and may actually be useful in the identification and medical follow-up of high-risk groups. LDL-C levels at diagnosis therefore emerge as a prognostic factor in $\mathrm{BC}$ patients.

For operable $\mathrm{BC}$, two years of follow up may be short, but is also reported that disease relapse has a peak of incidence in the first two years after diagnosis [70,71]. As a limitation we could not avoid the possible influence of adjuvant treatment either in lipid profile or disease progression, once no modification to the routine protocols was introduced. Nevertheless the strong association of LDL-C level and tumor size before treatment favors the LDL-C as a putative prognostic biomarker. It is also not possible to exclude the common association of cholesterol levels, obesity and the variance in health awareness before diagnosis. However results were adjusted to BMI and, during follow up, all women were evolved in the same program of surveillance and health control.

We can speculate that high LDL-C levels in patients with aggressive (high stage/ high grade) primary tumors 
have a cancer-fuelling effect and are a co-causative factor, in patients with chronic hypercholesterolemia. But, on the other hand, the high LDL-C levels that we observed may actually reflect a shift in cholesterol synthesis (by the liver or tumor cells themselves) in patients with aggressive tumors; accordingly, Zielinski et al. [72] followed-up a group of patients with advanced $\mathrm{BC}$ in remission and described a significant rise in plasma cholesterol and triglycerides in most of those who developed disease progression.

Considering that proliferating cancer cells have an increased demanding of cholesterol and intermediates of cholesterol biosynthesis pathway, the up-regulation of cholesterol biosynthesis and reduced cellular efflux are expected. In cancer cells, cholesterol synthesis has been shown to be increased, due to availability of precursors or to increased transcription [73], and this may have contributed to BC carcinogenesis [74,75]. Hidroxi-3methyl-glutaril-coA reductase 3 inhibition by statins decreases in vitro cell proliferation, attesting that cholesterol biosynthesis should be important to tumor growth [74]. Moreover, elevated cholesterol content is characteristic of breast tumors [76] and acyl-CoA: cholesterol acyltransferase 1 inhibition, an enzyme involved in cholesteryl esterification decreases proliferation and invasion rate [13].

However, despite cancer cells increases intracellular cholesterol synthesis, this effect is not expected to produce hypercholesterolemia and justify the observed associations.

Some other published data supports the notion that cancer cells are able to uptake cholesterol from the bloodstream. High LDL-C receptor expression was demonstrated in $\mathrm{BC}$ tissue, compared to normal tissue [77]. So plasma LDL-C could be used by cancer cells. In in vitro experiments, was also demonstrated that cancer cells can also consume HDL-C through the scavenger receptor class B, type I (SR-BI) $[15,16,78]$ and exogenous triglycerides [79]. In our clinical setting HDL-C or triglycerides measurements did not show suspicious modifications, but our results do not rule out the possibility of cancer cells consume.

Corroborating this hypothesis are laboratory studies showing that both exogenous LDL-C and HDL-C can promote proliferation and migration, features of aggressive tumors [14-16]. Also animal studies showed a higher tumor and metastatic burden [21] as well as disease progression $[22,23]$ in hypercholesterolemic mice compared with nonhypercholesterolemic controls.

The exogenous cholesterol could be mobilized from body storage, through HDL-C or from diet, through hepatic metabolism and LDL-C. Mobilization is not likely to contribute to hyperlipidemia, since we saw the same pattern of lipid profile in $\mathrm{BC}$ patients and in the age and sex-matched non-cancer portuguese population $[67,68]$.
High LDL-C and low HDL-C is the most common lipid profile induced by western diet and is highly frequent [80].

Initial studies on cholesterol and cancer showed an increased risk in patients with lower plasma cholesterol. Once demonstrated that reduction in cholesterol level does not cause cancer this has been assumed as a preclinical effect of malignancy considering that cancer cells up take cholesterol and decreases its levels. [62,63]. We found an association of LDL-C with large tumors, but all tumors were at very initial clinical phase, many of them diagnosed in screening programs.

The causal relationship between systemic cholesterol has been hard to demonstrate because of the length of time to the event, multifactorial etiology of $\mathrm{BC}$, concomitant medication, statistical analysis and event definitions. However, assuming that cholesterol is essential to cell proliferation, once a tumor develops in a hypercholesterolemic environment it is well adapted to progress and this may be the explanation for the observed association of LDL-C level, tumor size and disease progression.

We also found that tumors of the LDL-C highest tertile are more commonly Her2-neu (ErbB2) positive. Moreover, as mentioned earlier, membrane cholesterol is specially localized in the lipid rafts domains. Such areas are enriched in transmembrane molecules that are key in signaling pathways associated with malignant progression: Fas receptor, TNF related apoptosis-inducing ligand, AKT, integrins, cadherins and growth factor receptors [8] including ErbB2. The later is a tyrosine kinase receptor (and oncogene) localized in lipid rafts and its function is highly dependent on membrane fluidity [81,82]; cholesterol enrichment within the cell may therefore alter receptor-signaling. It is possible that ErbB2 receptor ligand-independent activation is potentiated by cholesterol-enriched environment, explaining a selection of Her2-neu positive tumors.

Although synthesis of estrogen and progesterone require cholesterol, no association of LDL-C and ER status was seen. In vitro and in vivo studies have showed contradictory results concerning the effect of cholesterol, in promoting ER positive breast cancer proliferation $[14,20]$.

The pro-inflammatory microenvironment induced by high-cholesterol levels, as seen in atherosclerosis, in which LDL-C is the most important causative factor $[83,84]$, can also play an effect on BC initiation and progression. The use of statins before cancer diagnosis reduces cancer related mortality [85]; the reduction of LDL-C is supposed to be the main mechanism through which statins exert effect, but the anti-inflammatory effect cannot be ruled out.

In our prospective study, patients with high levels of LDL-C at diagnosis had reduced disease free survival, even adjusting to tumor type, stage and BMI. This may 
reflect that high levels of LDL-C potentiate micrometatasis development or that hypercholesterolemia previously selected aggressive tumors but reinforces a role for systemic cholesterol in BC progression and cholesterol metabolism as a therapeutic target.

\section{Conclusion}

We found that LDL-C fraction is significantly associated with $\mathrm{BC}$ progression and may actually be useful in the identification and follow-up of high-risk groups of $\mathrm{BC}$ patients. LDL-C levels at diagnosis, therefore emerge as a prognostic factor in BC. Additionally, results support a role for systemic cholesterol in $\mathrm{BC}$ progression and indicate that cholesterol metabolism could be a therapeutic target in $\mathrm{BC}$ treatment.

\section{Additional files}

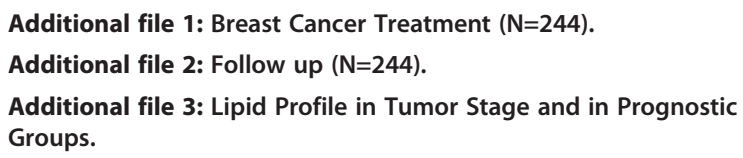

Additional file 5: Patient Characteristics in LDL-C level tertiles.

Additional file 6: Univariate Logistic Regression to the Risk of Tumor Size $\geq 20 \mathrm{~mm}$.

Additional file 7: Overall and Disease-free Survival in LDL-C Tertiles Groups adjusted to BMI. Kaplan-Meier Curves for overall survival and disease free survival to each BMI tertile. are shown. At 25 months of follow up disease-free survival shows differences across $L D L-C$ tertiles, BMI adjusted (Log rank test $P$ 0,018). But overall survival is not different in LDL-C tertiles (Log rank test 0,157 ).

\section{Competing interest}

The authors have no financial or non-financial competing interests.

\section{Authors' contribution}

CRS: Study design, patient enrollment, data collection and analysis, manuscript writing. IF: Pathological data validation and analysis, manuscript revision. SD: Study design, data analysis, manuscript writing. MA: Study supervision, data analysis, manuscript revision. All authors read and approved the final manuscript.

\section{Acknowledgments \\ We thank to the staff of Breast Unit and to the Pathology and Clinical Laboratories of IPOLFG for assistance in the clinical and pathological data collection, in particular to João Matos, from Pathology Department of IPOLFG, for the KI67 immunohistochemical staining and quantification. We especially thank to Tânia Carvalho (from Histology Service of Instituto de Medicina Molecular) for the critical review of the manuscript.}

\section{Funding}

Supported by the Programme to Advanced Medical Education (Fundação Gulbenkian, Fundação Champalimaud, Fundação para a Ciência e Tecnologia, Ministério da Saúde) (CRS). Fundação para a Ciência e Tecnologia (PTDC/SAU-ONC/114080/2009)(SD).

\section{Author details}

${ }^{1}$ Gulbenkian Programme for Advanced Medical Education, Lisbon, Portugal. ${ }^{2}$ Department of Surgical Oncology, Instituto Português de Oncologia de Lisboa, Francisco Gentil, Lisbon, Portugal. ${ }^{3}$ Department of Pathology, Instituto Português de Oncologia de Lisboa, Francisco Gentil, Lisbon, Portugal. ${ }^{4}$ Instituto de Medicina Molecular, Lisbon, Portugal. ${ }^{5}$ Faculdade de Medicina de Lisboa, Lisbon, Portugal.

Received: 4 October 2013 Accepted: 13 February 2014 Published: 26 February 2014

\section{References}

1. Eurostat. http://epp.eurostat.ec.europa.eu accessed on 27July2013.

2. Centers for Disease Control and Prevention. www.cdc.gov accessed on 27 July 2013.

3. He J, Gu D, Wu X, Reynolds K, Duan X, Yao C, Wang J, Chen CS, Chen J, Wildman RP, Klag MJ, Whelton PK: Major causes of death among men and women in China. New Engl J Med 2005, 353(11):1124-1134.

4. World Health Organization. www.who.int accessed on 27 July 2013.

5. Ferlay JSH, Bray F, Forman D, Mathers C, Parkin DM: GLOBOCAN 2008 v2.0 Cancer Incidence and Mortality Worldwide: IARC CancerBase No. 10Lyon, France: International Agency for Research on Cancer; 2010 http://globocan.iarc.fr/, accessed on 27 July 2013.

6. Jin F, Shu XO, Devesa SS, Zheng W, Blot WJ, Gao YT: Incidence trends for cancers of the breast, ovary, and corpus uteri in urban Shanghai, 1972-89. Canc Causes Contr 1993, 4(4):355-360.

7. Smith D: Epidemiology of dyslipidemia and economic burden on the healthcare system. Am J Manag Care 2007, 13(Suppl 3):S68-S71.

8. Lingwood D, Simons K: Lipid rafts as a membrane-organizing principle. Science 2010, 327(5961):46-50.

9. Babina IS DS, Nabi IR, Hopkins AM: Lipid rafts as master regulators of breast cancer cell function. In Breast Cancer - Carcinogenesis, Cell Growth and Signalling Pathways. Edited by Gunduz M, Gunduz E, InTech; 2011. ISBN ISBN 978-953-307-714-7 2011.

10. Yager JD, Davidson NE: Estrogen carcinogenesis in breast cancer. N Engl J Med 2006, 354(3):270-282.

11. Bray F, McCarron P, Parkin DM: The changing global patterns of female breast cancer incidence and mortality. Breast Cancer Res 2004, 6(6):229-239.

12. Steinhagen-Thiessen $E$, Bramlage $P$, Losch $C$, Hauner $H$, Schunkert $H$, Vogt $A$ Wasem J, Jockel KH, Moebus S: Dyslipidemia in primary care-prevalence, recognition, treatment and control: data from the German Metabolic and Cardiovascular Risk Project (GEMCAS). Cardiovasc Diabetol 2008, 7:31

13. Antalis CJ, Arnold T, Rasool T, Lee B, Buhman KK, Siddiqui RA: High ACAT1 expression in estrogen receptor negative basal-like breast cancer cells is associated with LDL-induced proliferation. Breast Cancer Res Treat 2010, 122(3):661-670.

14. Antalis CJ, Uchida A, Buhman KK, Siddiqui RA: Migration of MDA-MB-231 breast cancer cells depends on the availability of exogenous lipids and cholesterol esterification. Clin Exp Metastasis 2011, 28(8):733-741.

15. Pussinen PJ, Karten B, Wintersperger A, Reicher H, McLean M, Malle E, Sattler W: The human breast carcinoma cell line HBL-100 acquires exogenous cholesterol from high-density lipoprotein via CLA-1 (CD-36 and LIMPII analogous 1)-mediated selective cholesteryl ester uptake. Biochem $J$ 2000, 349(Pt 2):559-566.

16. Danilo C, Gutierrez-Pajares JL, Mainieri MA, Mercier I, Lisanti MP, Frank PG: Scavenger receptor class B type I regulates cellular cholesterol metabolism and cell signaling associated with breast cancer development. Breast Cancer Res 2013, 15(5):R87.

17. Pan B, Ren H, Lv X, Zhao Y, Yu B, He Y, Ma Y, Niu C, Kong J, Yu F, Sun WB, Zhang $Y$, Willard $B$, Zheng $L$ : Hypochlorite-induced oxidative stress elevates the capability of HDL in promoting breast cancer metastasis. $J$ Transl Med 2012, 10:65

18. Pan B, Ren H, He Y, Lv X, Ma Y, Li J, Huang L, Yu B, Kong J, Niu C, Zhang Y, Sun WB, Zheng L: HDL of patients with type 2 diabetes mellitus elevates the capability of promoting breast cancer metastasis. Clin Canc Res 2012 18(5):1246-1256.

19. Pan B, Ren H, Ma Y, Liu D, Yu B, Ji L, Pan L, Li J, Yang L, Lv X, Shen X, Chen B, Zhang $Y$, Willard B, He Y, Zheng L: High-density lipoprotein of patients with type 2 diabetes mellitus elevates the capability of promoting migration and invasion of breast cancer cells. Int J Cancer 2012, 131(1):70-82. 
20. Nelson ER, Wardell SE, Jasper JS, Park S, Suchindran S, Howe MK, Carver NJ Pillai RV, Sullivan PM, Sondhi V, Umetani M, Geradts J, McDonnell DP: 27Hydroxycholesterol links hypercholesterolemia and breast cancer pathophysiology. Science 2013, 342(6162):1094-1098.

21. Llaverias G, Danilo C, Mercier I, Daumer K, Capozza F, Williams TM, Sotgia F Lisanti MP. Frank PG: Role of cholesterol in the development and progression of breast cancer. Am J Pathol 2011, 178(1):402-412.

22. Alikhani N, Ferguson RD, Novosyadlyy R, Gallagher EJ, Scheinman EJ, Yakar S, LeRoith D: Mammary tumor growth and pulmonary metastasis are enhanced in a hyperlipidemic mouse model. Oncogene 2013, 32(8):961-967.

23. Kim EJ, Choi MR, Park H, Kim M, Hong JE, Lee JY, Chun HS, Lee KW, Yoon Park JH: Dietary fat increases solid tumor growth and metastasis of 4 T1 murine mammary carcinoma cells and mortality in obesity-resistant BALB/c mice. Breast Cancer Res 2011, 13(4):R78.

24. Kitahara CM, de Gonzalez Berrington A, Freedman ND, Huxley R, Mok Y, Jee SH, Samet JM: Total cholesterol and cancer risk in a large prospective study in Korea. J Clin Oncol 2011, 29(12):1592-1598.

25. Wallace RB, Rost C, Burmeister LF, Pomrehn PR: Cancer incidence in humans: relationship to plasma lipids and relative weight. J Natl Cancer Inst 1982, 68(6):915-918

26. Kaye JA, Meier CR, Walker AM, Jick H: Statin use, hyperlipidemia, and the risk of breast cancer. Br J Cancer 2002, 86(9):1436-1439.

27. Emaus A, Veierod MB, Tretli S, Finstad SE, Selmer R, Furberg AS, Bernstein L, Schlichting E, Thune I: Metabolic profile, physical activity, and mortality in breast cancer patients. Breast Cancer Res Treat 2010, 121(3):651-660.

28. Iso H, Ikeda A, Inoue M, Sato S, Tsugane S: Serum cholesterol levels in relation to the incidence of cancer: the JPHC study cohorts. Int J Cancer 2009, 125(11):2679-2686.

29. Hoyer AP, Engholm G: Serum lipids and breast cancer risk: a cohort study of 5,207 Danish women. Cancer Causes Control 1992, 3(5):403-408.

30. Eliassen AH, Colditz GA, Rosner B, Willett WC, Hankinson SE: Serum lipids, lipid-lowering drugs, and the risk of breast cancer. Arch Intern Med 2005, 165(19):2264-2271

31. Gaard M, Tretli S, Urdal P: Risk of breast cancer in relation to blood lipids: a prospective study of 31,209 Norwegian women. Cancer Causes Control 1994, 5(6):501-509.

32. Hiatt RA, Fireman $\mathrm{BH}$ : Serum cholesterol and the incidence of cancer in a large cohort. J Chron Dis 1986, 39(11):861-870.

33. Ha M, Sung J, Song YM: Serum total cholesterol and the risk of breast cancer in postmenopausal Korean women. Cancer Causes Control 2009, 20(7):1055-1060.

34. Tornberg SA, Holm LE, Carstensen JM: Breast cancer risk in relation to serum cholesterol, serum beta-lipoprotein, height, weight, and blood pressure. Acta Oncol 1988, 27(1):31-37.

35. Vatten LJ, Foss OP: Total serum cholesterol and triglycerides and risk of breast cancer: a prospective study of 24,329 Norwegian women. Canc Res 1990, 50(8):2341-2346.

36. Tulinius $H$, Sigfusson N, Sigvaldason $H$, Bjarnadottir K, Tryggvadottir L: Risk factors for malignant diseases: a cohort study on a population of 22,946 Icelanders. Canc Epidemiol Biomarkers Prev 1997, 6(11):863-873.

37. Strohmaier S, Edlinger M, Manjer J, Stocks T, Bjørge T, Borena W, Häggström C, Engeland A, Nagel G, Almquist M, Selmer R, Tretli S, Concin H, Hallmans G, Jonsson H, Stattin P, Ulmer H: Total serum cholesterol and cancer incidence in the Metabolic syndrome and Cancer Project (Me-Can). PloS One 2013, 8(1):e54242.

38. Hegele RA: Plasma lipoproteins: genetic influences and clinical implications. Nat Rev Genet 2009, 10(2):109-121.

39. Furberg AS, Veierod MB, Wilsgaard T, Bernstein L, Thune I: Serum high-density lipoprotein cholesterol, metabolic profile, and breast cancer risk. J Natl Cancer Inst 2004, 96(15):1152-1160.

40. Kucharska-Newton AM, Rosamond WD, Mink PJ, Alberg AJ, Shahar E, Folsom AR: HDL-cholesterol and incidence of breast cancer in the ARIC cohort study. Ann Epidemiol 2008, 18(9):671-677.

41. Ray G, Husain SA: Role of lipids, lipoproteins and vitamins in women with breast cancer. Clin Biochem 2001, 34(1):71-76.

42. Michalaki V, Koutroulis G, Syrigos K, Piperi C, Kalofoutis A: Evaluation of serum lipids and high-density lipoprotein subfractions (HDL2, HDL3) in postmenopausal patients with breast cancer. Mol Cell Biochem 2005, 268(1-2):19-24.
43. Kim Y, Park SK, Han W, Kim DH, Hong YC, Ha EH, Ahn SH, Noh DY, Kang D, Yoo KY: Serum high-density lipoprotein cholesterol and breast cancer risk by menopausal status, body mass index, and hormonal receptor in Korea. Canc Epidemiol Biomarkers Prev 2009, 18(2):508-515.

44. Moorman PG, Hulka BS, Hiatt RA, Krieger N, Newman B, Vogelman JH, Orentreich N: Association between high-density lipoprotein cholesterol and breast cancer varies by menopausal status. Canc Epidemiol Biomarkers Prev 1998, 7(6):483-488.

45. Kabat GC, Kim M, Chlebowski RT, Khandekar J, Ko MG, McTiernan A, Neuhouser ML, Parker DR, Shikany JM, Stefanick ML, Thomson CA, Rohan TE: A longitudinal study of the metabolic syndrome and risk of postmenopausal breast cancer. Canc Epidemiol Biomarkers Prev 2009, 18(7):2046-2053.

46. Rosato V, Bosetti C, Talamini R, Levi F, Montella M, Giacosa A, Negri E, La Vecchia C: Metabolic syndrome and the risk of breast cancer in postmenopausal women. Ann Oncol 2011, 22(12):2687-2692.

47. Boyd NF, McGuire V: Evidence of association between plasma high-density lipoprotein cholesterol and risk factors for breast cancer. J Natl Cancer Inst 1990, 82(6):460-468.

48. Ferraroni M, Gerber M, Decarli A, Richardson S, Marubini E, de Crastes Paulet $\mathrm{P}$, de Crastes Paulet A, Pujol H: HDL-cholesterol and breast cancer: a joint study in northern Italy and southern France. Int J Epidemio/ 1993, 22(5):772-780.

49. Bani IA, Williams CM, Boulter PS, Dickerson JW: Plasma lipids and prolactin in patients with breast cancer. Br J Cancer 1986, 54(3):439-446.

50. Hasija K, Bagga HK: Alterations of serum cholesterol and serum lipoprotein in breast cancer of women. Indian J Clin Biochem 2005, 20(1):61-66.

51. Lopez-Saez JB, Martinez-Rubio JA, Alvarez MM, Carrera CG, Dominguez Villar M, de Lomas Mier AG, Domenech C, Senra-Varela A: Metabolic profile of breast cancer in a population of women in southern Spain. Open Clin Cancer J 2008, 2:1-6.

52. Abdelsalam KE, Hassan IK, Sadig IA: The role of developing breast cancer in alteration of serum lipid profile. J Res Med Sci 2012, 17(6):562-565.

53. Owiredu WK, Donkor S, Addai BW, Amidu N: Serum lipid profile of breast cancer patients. Pak J Biol Sci 2009, 12(4):332-338.

54. Yadav NK, Poudel B, Thanpari C, Chandra Koner B: Assessment of biochemical profiles in premenopausal and postmenopausal women with breast cancer. Asian Pac J Cancer Prev 2012, 13(7):3385-3388.

55. Potischman N, McCulloch CE, Byers T, Houghton L, Nemoto T, Graham S, Campbell TC: Associations between breast cancer, plasma triglycerides, and cholesterol. Nutr Cancer 1991, 15(3-4):205-215.

56. Knapp ML, al-Sheibani S, Riches PG: Alterations of serum lipids in breast cancer: effects of disease activity, treatment, and hormonal factors. Clin Chem 1991, 37(12):2093-2101.

57. Agurs-Collins T, Kim KS, Dunston GM, Adams-Campbell LL: Plasma lipid alterations in African-American women with breast cancer. $J$ Cancer Res Clin Oncol 1998, 124(3-4):186-190.

58. Edge SB, Compton CC: The American Joint Committee on Cancer: the 7th edition of the AJCC cancer staging manual and the future of TNM. Ann Surg Oncol 2010, 17(6):1471-1474.

59. NCCN: Clinical Practice Guidelines in Oncology. http://www.ncen.org accessed on 27 July 2013

60. WHO classification of tumours of the breas. Edited by Lakhani SR El, Schnitt SJ, Tan PH, van de Vijver MJ. Lyon: IARC; 2012:22-23.

61. Blows FM, Driver KE, Schmidt MK, Broeks A, van Leeuwen FE, Wesseling J, Cheang MC, Gelmon K, Nielsen TO, Blomqvist C, Heikkilä P, Heikkinen T, Nevanlinna H, Akslen LA, Bégin LR, Foulkes WD, Couch FJ, Wang X, Cafourek V, Olson JE, Baglietto L, Giles GG, Severi G, McLean CA, Southey MC, Rakha E, Green AR, Ellis IO, Sherman ME, Lissowska J, Anderson WF, Cox A, Cross SS, Reed MW, Provenzano E, Dawson SJ, Dunning AM, Humphreys M, Easton DF, García-Closas M, Caldas C, Pharoah PD, Huntsman D: Subtyping of breast cancer by immunohistochemistry to investigate a relationship between subtype and short and long term survival: a collaborative analysis of data for 10,159 cases from 12 studies. PLoS Med 2010, 7(5):e1000279.

62. Kritz H, Zielinski C, Sinzinger H: Low cholesterol and cancer. J Clin Oncol 1996, 14(11):3043-3048.

63. Trompet S, Jukema JW, Katan MB, Blauw GJ, Sattar N, Buckley B, Caslake M, Ford I, Shepherd J, Westendorp RG, de Craen AJ: Apolipoprotein e genotype, plasma cholesterol, and cancer: a Mendelian randomization study. Am J Epidemio/ 2009, 170(11):1415-1421.

64. Costa JBM, Oliveira M, Gouveia M, Carneiro AV: Incidence and prevalence of hypercholesterolemia in Portugal: a systematic review. Part III. Portuguese Journal of Cardiology 2003, 22(6):829-836. 
65. Kwan ML, Kushi LH, Weltzien E, Maring B, Kutner SE, Fulton RS, Lee MM, Ambrosone CB, Caan BJ: Epidemiology of breast cancer subtypes in two prospective cohort studies of breast cancer survivors. Breast Canc Res 2009, 11(3):R31.

66. Lund EB M, Hair B, Ward K, Andrews J, Bayakly A, Gabram S, O'Regan R, Eley J: A first report of incidence rates (Not Prevalence) by breast cancer subtypes. Cancer Res 2009, 69(Issue 24, Supplement 3):Abstract 3065.

67. Cortez-Dias N, Robalo Martins S, Belo A, Fiuza M, em nome dos Investigadores do Estudo V: Characterization of lipid profile in primary health care users in Portugal. Portuguese Journal Of Cardiology 2013, 32(12):987-996.

68. Pina LC, Castro AR, Silva C: Tensão arterial em três distritos de Portugal FCS. Trabalhos de Conclusão de Graduação 2008, http://bdigital.ufp.pt accessed on 27 July 2013.

69. de Azambuja E, Cardoso F, de Castro G Jr, Colozza M, Mano MS, Durbecq V, Sotiriou C, Larsimont D, Piccart-Gebhart MJ, Paesmans M: Ki-67 as prognostic marker in early breast cancer: a meta-analysis of published studies involving 12,155 patients. Br J Cancer 2007, 96(10):1504-1513.

70. Khatcheressian JL, Hurley P, Bantug E, Esserman L, Grunfeld E, Halberg F, Hantel A, Henry NL, Muss HB, Smith TJ, Vogel VG, Wolff AC, Somerfield MR, Davidson NE, American Society of Clinical Oncology: Breast cancer follow-up and management after primary treatment: American Society of Clinical Oncology clinical practice guideline update. J Clin Oncol 2013, 31(7):961-965.

71. Demicheli R, Abbattista A, Miceli R, Valagussa P, Bonadonna G: Time distribution of the recurrence risk for breast cancer patients undergoing mastectomy: further support about the concept of tumor dormancy. Breast Canc Res Treat 1996, 41(2):177-185.

72. Zielinski CC, Stuller I, Rausch P, Muller C: Increased serum concentrations of cholesterol and triglycerides in the progression of breast cancer. J Cancer Res Clin Oncol 1988, 114(5):514-518.

73. DeBerardinis RJ, Lum JJ, Hatzivassiliou G, Thompson CB: The biology of cancer: metabolic reprogramming fuels cell growth and proliferation. Cell Metabol 2008, 7(1):11-20.

74. Clendening JW, Pandyra A, Boutros PC, El Ghamrasni S, Khosravi F, Trentin GA, Martirosyan A, Hakem A, Hakem R, Jurisica I, Penn LZ: Dysregulation of the mevalonate pathway promotes transformation. Proc Natl Acad Sci U S A 2010, 107(34):15051-15056

75. Ginestier C, Monville F, Wicinski J, Cabaud O, Cervera N, Josselin E, Finetti P, Guille A, Larderet G, Viens P, Sebti S, Bertucci F, Birnbaum D, Charafe-Jauffret E: Mevalonate metabolism regulates Basal breast cancer stem cells and is a potential therapeutic target. Stem cells 2012, 30(7):1327-1337.

76. Martin BJ, VGK: A comparison of cholesterol uptake and storage in inflammatory and non inflammatory breast cancer cells. Int J Breast Cancer 2012, 2012: Article ID 412581, 10 pages accessed on 27 July 2013.

77. Pires LA, Hegg R, Freitas ER, Tavares ER, Almeida CP, Baracat EC, Maranhao RC: Effect of neoadjuvant chemotherapy on low-density lipoprotein (LDL) receptor and LDL receptor-related protein 1 (LRP-1) receptor in locally advanced breast cancer. Braz J Med Biol Res 2012, 45(6):557-564.

78. Cao WM, Murao K, Imachi H, Yu X, Abe H, Yamauchi A, Niimi M, Miyauchi A Wong NC, Ishida T: A mutant high-density lipoprotein receptor inhibits proliferation of human breast cancer cells. Canc Res 2004, 64(4):1515-1521.

79. Nomura DK, Long JZ, Niessen S, Hoover HS, Ng SW, Cravatt BF: Monoacylglycerol lipase regulates a fatty acid network that promotes cancer pathogenesis. Cell 2010, 140(1):49-61.

80. Mendis SPP, Norrving B: in Global Atlas on Cardiovascular Disease Prevention and Control. Geneva: World Health Organization (in collaboration with the World Heart Federation and World Stroke Organization); 2011.

81. Sigismund S, Argenzio E, Tosoni D, Cavallaro E, Polo S, Di Fiore PP: Clathrinmediated internalization is essential for sustained EGFR signaling but dispensable for degradation. Dev Cell 2008, 15(2):209-219.

82. Orr G, Hu D, Ozcelik S, Opresko LK, Wiley HS, Colson SD: Cholesterol dictates the freedom of EGF receptors and HER2 in the plane of the membrane. Biophys J 2005, 89(2):1362-1373.
83. Ross R: Atherosclerosis-an inflammatory disease. New Engl J Med 1999, 340(2):115-126.

84. Hansson GK, Libby P: The immune response in atherosclerosis: a double-edged sword. Nat Rev Immunol 2006, 6(7):508-519.

85. Nielsen SF, Nordestgaard BG, Bojesen SE: Statin use and reduced cancer-related mortality. New Engl J Med 2012, 367(19):1792-1802.

doi:10.1186/1471-2407-14-132

Cite this article as: Rodrigues dos Santos et al:: Plasma level of LDL-cholesterol at diagnosis is a predictor factor of breast tumor progression. BMC Cancer 2014 14:132.

\section{Submit your next manuscript to BioMed Central and take full advantage of:}

- Convenient online submission

- Thorough peer review

- No space constraints or color figure charges

- Immediate publication on acceptance

- Inclusion in PubMed, CAS, Scopus and Google Scholar

- Research which is freely available for redistribution

Submit your manuscript at www.biomedcentral.com/submit
C) Biomed Central 